\title{
IMAGENS LANDSAT-7/ETM+ E SRTM COMO FERRAMENTAS AUXILIARES NA IDENTIFICAÇÃO DE PERFIS LATERÍTICOS - EXEMPLO EM BOM JESUS DA PENHA (MG).
}

\author{
LANDSAT-7/ETM + AND SRTM IMAGES AS AUXILIARY TOOLS TO IDENTIFY LATERITIC \\ PROFILES - EXAMPLE IN BOM JESUS DA PENHA (MG).
}

\author{
Ilio Rodarte FARIA JÚNIOR ${ }^{1}$; George Luiz LUVIZOTTO²; Vania ROSOLEN ${ }^{2}$ \\ ${ }^{1}$ Programa de Pós-Graduação em Geociências e Meio Ambiente, Universidade Estadual Paulista - UNESP. Rio Claro - SP. \\ Email: rdt.ilio@gmail.com; \\ ${ }^{2}$ Departamento de Petrologia e Metalogenia - DPM, Universidade Estadual Paulista - UNESP. Rio Claro - SP. CEP 13506-900. \\ Email: georgell@rc.unesp.br; vrosolen@rc.unesp.br
}

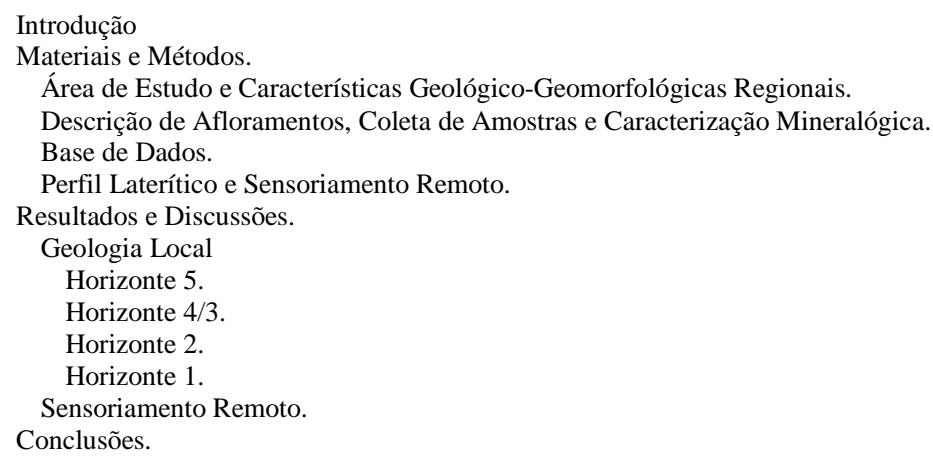

\begin{abstract}
RESUMO - Os perfis lateríticos cobrem vasta área do território brasileiro e seus estudos são motivados por fins diversos. Internamente se estruturam na forma de horizontes com variação vertical de suas composições químicas e mineralógicas. $\mathrm{O}$ desenvolvimento e preservação dos perfis lateríticos são indissociáveis das características do modelado, fazendo com que as exposições dos horizontes de um evento de intemperismo se associem a determinadas feições e posições do relevo. Tomando por base variações químico-mineralógicas e posição no relevo, é possível aplicar técnicas de sensoriamento remoto para delimitar respostas desses horizontes de intemperismo quando aflorantes. Assim, o presente trabalho teve por objetivo a descrição e caracterização de um perfil laterítico na região de Bom Jesus da Penha (MG) seguido da busca de relações desse perfil com as respostas de sensoriamento remoto com imagens de satélite Landsat-7/ETM+ e modelos digitais de relevo gerados por imagem de radar SRTM 1Arc-sec. Essa região é marcada por um planalto parcialmente recortado por escarpas, permitindo exposições de horizontes do perfil de intemperismo identificado regionalmente, o que favorece a aplicação do sensoriamento remoto. Na região estudada o perfil de intemperismo se desenvolve a partir de gnaisses, clorita-anfibólio xistos e quartzitos. Para contribuir com a tipificação do perfil laterítico foi feita a caracterização mineralógica (difração de raio X) dos horizontes de intemperismo do domínio do xisto metaultramáfico. Como resultado, a aplicação do sensoriamento remoto permitiu a delimitação de áreas com características relacionáveis aos horizontes superiores do perfil laterítico identificado em campo.
\end{abstract}

Palavras-chave: Sensoriamento remoto; Perfil de intemperismo; Greenstone Belt Morro do Ferro; Rocha metaultramáfica.

\begin{abstract}
The Brazilian territory has large areas covered by lateritic profiles and their studies have diverse motives. These profiles shows an internal structure with horizons that vary, vertically, in their chemical and mineralogical compositions, and the development of the lateritic processes is inseparable from the characteristics of the model. Then, the exposures of the horizons of a weathering event are associated to features and positions of the relief. Using chemical-mineralogical variations and position on the relief, it is possible apply remote sensing techniques to delimitate answers from those outcrops horizons. Here, the characterization of a lateritic profile neighbor to Bom Jesus da Penha town (MG), developed from gneisses, chlorite-amphibole schists and quartzites, was made by mineralogical characterizations (X-ray diffraction) of samples from different horizons of the metaultramafic schist domain. In sequence, were applied spectral compositions of Landsat-7/ETM+ satellite images and digital elevations and declivity models of the relief, generated by SRTM 1Arc-sec radar images. Thus, the objective was to identify spectral answers to distinct weathering horizons described in the fieldwork. This remote sensing treatment allowed to delimit areas with characteristics related to the superior horizons of the lateritic profile identified in the fieldwork.
\end{abstract}

Keywords: Remote sensing; Weathering profile; Greenstone Belt Morro do Ferro; Metaultramafic rock.

\section{INTRODUÇÃO}

Os perfis lateríticos são resultados de intenso intemperismo de rochas em condições de clima tropical a subtropical, comuns na paisagem brasileira, cuja importância vai desde o ponto de vista econômico (mineração e agricultura) até a obtenção de uma boa interação do homem com o meio geológico
(Melfi et al., 1980; Dardenne \& Schobbenhaus, 2001; Retallack, 2010). A gênese de um perfil laterítico é consequência de processos que transformam profundamente o substrato geológico. Internamente seus horizontes lateríticos se formam pela alteração de minerais pré-existentes a partir 
da reação de hidrólise com as águas pluviais ácidas (Butt, 1975; Smirnov, 1982), influenciados ainda pelos próprios litotipos, condições de potencial de hidrogênio $(\mathrm{pH})$ e potencial de oxidação (Eh), de drenagem do terreno, de estabilidade tectônica e oscilações pluviométricas e térmicas (Brand et al., 1998; Thorne, 2011; Marsh et al., 2013).

Foi descrito aqui, em visita de campo, um perfil laterítico na região de Bom Jesus da Penha (MG), o qual se desenvolveu a partir de gnaisses, clorita-anfibólio xistos e quartzitos. $\mathrm{Na}$ sequência, buscou-se investigar, com sensoriamento remoto, a distribuição espacial dos horizontes de intemperismo do perfil laterítico, o que foi feito com base em composições de bandas de imagens Landsat-7 e posições no relevo (SRTM 1 Arc-sec). Perfis lateríticos apresentam certa resistência ao processo erosivo (Melfi et al., 1980), o que não impede de terem seus horizontes internos expostos parcial ou totalmente em escarpas ou meiaencostas (Marsh et al., 2013). Essas condições de exposição parcial conformam o modelo para aplicação de sensoriamento remoto para determinar a presença e extensão desse perfil.

A investigação dos perfis lateríticos com uso de Landsat-7/ETM+ foi alvo de uma série de trabalhos, como Soe et al. (2008), Dogan (2009) e Madeira et al. (2010). Aqui optou-se por aplicar as composições propostas por Andrews Deller (2006) para imagens de satélite Landsat-7/ETM+. Junto disso, também se utilizou a mesma subdivisão do perfil laterítico aplicada por esse autor, o que permitiu estabelecer comparações entre o presente trabalho e aquele de referência, mesmo existindo distintas condições ambientais entre os dois locais estudados.

\section{MATERIAIS E MÉTODOS}

Área de Estudo e Características GeológicoGeomorfológicas Regionais.

A área de estudo, cuja porção central se situa nas coordenadas $20^{\circ} 599^{\prime} 6.03^{\prime \prime S}, 46^{\circ} 29^{\prime} 34.78 " \mathrm{O}$, localiza-se no sudoeste de Minas Gerais (Figura 1), cortada pela Rodovia BR-265, aproximadamente $6 \mathrm{~km}$ a nordeste (NE) da cidade de Bom Jesus da Penha.
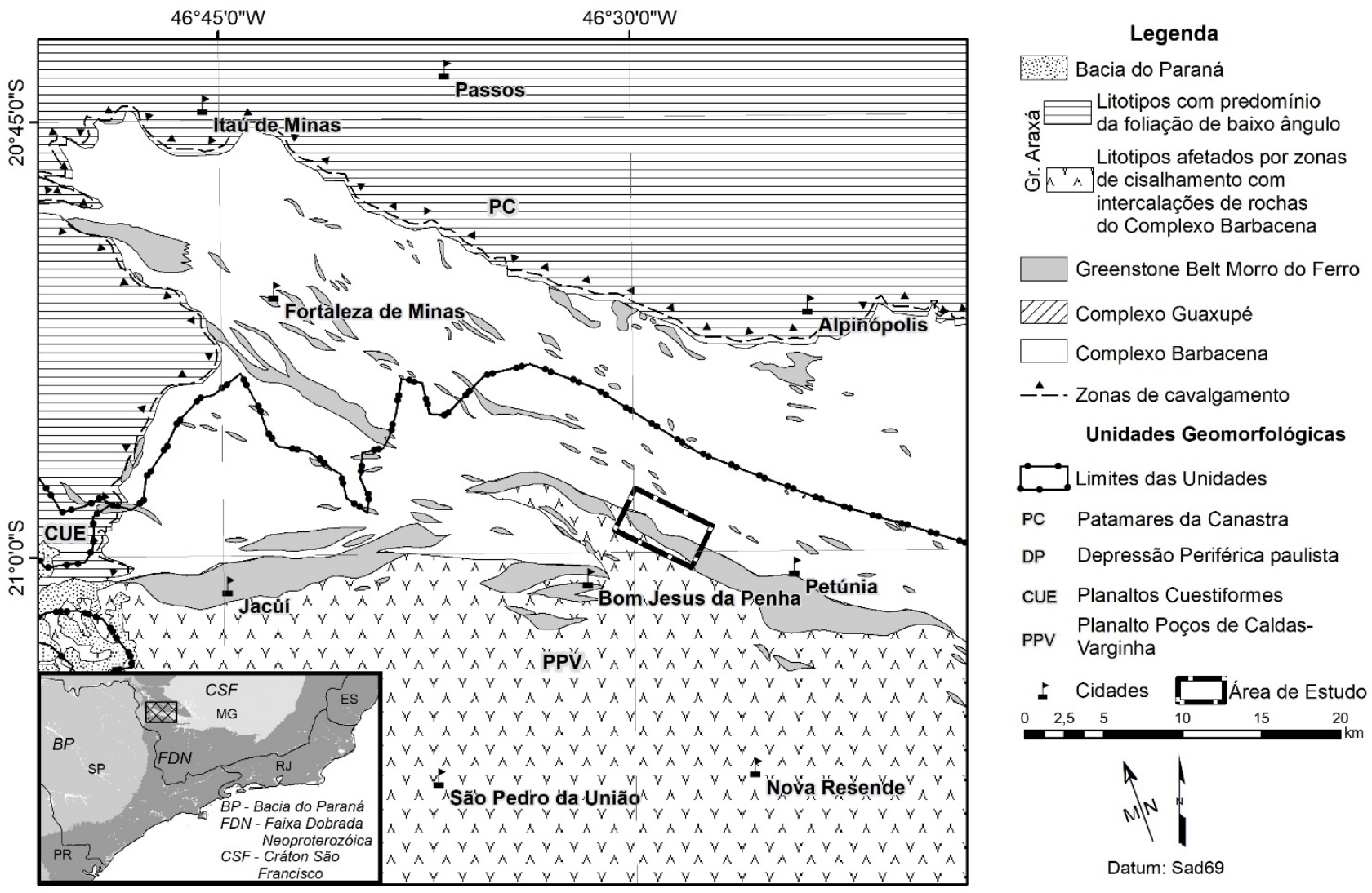

Figura 1 - Mapa geológico regional (adaptado de Zanardo, 2003), unidades geomorfológicas (modificado de RADAMBRASIL, 1983) e localização da área de estudos. 
Está situada na porção limítrofe dos litotipos aflorantes do Cráton São Francisco e da Província Estrutural Tocantins (Almeida, 1981), com unidades geológicas de evoluções tectonometamórficas, de idades e gêneses distintas (Almeida, 1981; Zanardo, 1992; Brito Neves et al., 1999; Valeriano et al., 2004).

Na região aflora um terreno tipo granitogreenstone, pertencente ao Cráton São Francisco (Almeida, 1981). O Complexo Barbacena, domínio arqueano/ paleoproterozóico, é composto por granitóides e biotita e/ou anfibólio gnaisses bandados (Hasui et al., 1988; Zanardo, 1992). O Greenstone Belt Morro do Ferro (GBMF) (Teixeira, 1978) é composto por sequências metavulcanossedimentares na forma de faixas alongadas segundo a direção oeste-noroeste (WNW), com ramificação para na direção leste-oeste (E-W) na região de Jacuí, que estão inseridas, por contatos tectônicos, no Complexo Barbacena e no Grupo Araxá (Feola, 2004). Nessa unidade predominam rochas metaultramáficas e metabásicas, ambas de composição komatiítica, chegando a toleítica na segunda, e, em menor escala, cálcio alcalina (Teixeira \& Danni, 1979; Carvalho et al., 1992; Zanardo, 1992, 2003).

O Grupo Araxá, domínio Neoproterozóico, é representado por uma sequência metassedimentar com contribuição de rochas vulcânicas e vulcanoclásticas (Zanardo et al., 1990; Simões, 1995). Essa unidade se instala na forma de nappe de cavalgamento de baixo ângulo, com vergência de W para E (Simões, 1995). No fim do evento Brasiliano todas essas unidades foram afetadas, em diferentes graus, por sistemas de cisalhamento direcionais (Morales, 1993).

As características lito-estruturais são fundamentais na evolução do modelo, e, por consequência, na compartimentação geomorfológica e suas respectivas unidades, fatores que influenciam fortemente a gênese e preservação dos perfis lateríticos. A área de estudo se insere na unidade geomorfológica Planalto Poços de Caldas-Varginha (Figura 1), composta por colinas e morros alongados, com vertentes convexas ou côncavas e topos convexos ou aplanados. Predominam os Latossolos Vermelho-amarelo e Vermelho-escuro, podendo ocorrer Argissolos e Cambissolos (RADAMBRASIL, 1983), características essas que, somadas, são propícias à presença e preservação de pronunciados perfis de intemperismo.

Descrição de Afloramentos, Coleta de Amostras e Caracterização Mineralógica

A unidade geomorfológica Planalto Poços de Caldas-Varginha abriga perfis lateríticos com grande extensão lateral. Esse domínio é representado por morros de topo convexo ou aplanado, onde se identificam perfis de intemperismo tipicamente profundos, cujas espessuras variam lateralmente de acordo com litotipos e demais condições que regem sua gênese. A área aqui abordada se encontra nessa unidade, o que leva à sua associação com o perfil laterítico aqui identificado.

Em condições naturais é incomum se observar toda extensão vertical de um perfil laterítico, situação que não foi diferente nessa área estuada. Assim, os distintos horizontes foram identificados expostos em diferentes posições do relevo e, portanto, distribuídos ao longo da poligonal destacada. Dessa forma, para compor o quadro total desse perfil laterítico foram descritos, durante a etapa de campo, as rochas não intemperizadas, quando aflorantes, e seus horizontes de intemperismo.

O clorita-anfibólio xisto foi o litotipo que embasou a coletas de amostras (nomeadas com a sigla IRF) para caracterizações mineralógicas e para representação do perfil laterítico, dado sua maior representatividade. Essa condição se deve às suas melhores exposições de horizontes de intemperismo, a exemplo do corte de estrada na porção central da área estudada, onde se observa boa distinção entre os horizontes 5 e 4/3, local onde se coletou a maioria das amostras para caracterização mineralógica.

A caracterização mineralógica de amostra total foi feita por difratometria de raios X. Para isso, se utilizou o equipamento PANalytical EMPYREAN (Departamento de Petrologia e Metalogenia da UNESP - Rio Claro), com radiação de cobre ( $W L=1,54056 \AA$ ) e filtro de níquel, ao passo de 3,8” e tamanho do passo de $0,008^{\circ}$ (velocidade de scan de $0,27^{\circ} / \mathrm{s}$ ), no intervalo de $3^{\circ}<2 \theta<65^{\circ}$, com corrente de $30 \mathrm{~mA}$ e voltagem de $40 \mathrm{kV}$.

A descrição petrográfica da seção delgada da rocha foi feita por luz transmitida em microscópio óptico convencional, ZeissAxioskop A1. 


\section{Bases de Dados Satelitais}

Para esse trabalho, foi utilizada uma imagem de satélite Landsat-7/ETM + (path 219/row 075, de agosto de 2000 - http://landsat.org/, cuja base de dados migrou para https://earthexplorer. usgs.gov/), com resolução de $30 \mathrm{~m}$, na qual se aplicou correção atmosférica com base na operação "DarkSubtract”, disponível no suíte de ferramentas do software ENVI 4.1, no qual foram feitas também as composições de bandas (RGB 742 e 754).

Os modelos de elevação e declividade do relevo foram elaborados com base nas imagens da missão do ônibus espacial de topografia por radar (acrônimo em inglês SRTM (https://earthexplorer.usgs.gov/), com resolução espacial de $30 \mathrm{~m}$ (1Arc-sec), as quais foram manipuladas no software ArcMap 10 (parte do ArcGIS 10). O mesmo software também foi utilizado para integrar os dados de satélite, radar, a base geológica adaptada de Zanardo (2003) e Feola (2004) e as informações coletadas em campo.

\section{Perfil Laterítico e Sensoriamento Remoto}

Perfis lateríticos apresentam certa resistência ao processo erosivo (Melfi et al., 1980), o que não impede de terem seus horizontes internos expostos parcial ou totalmente em escarpas ou meia-encostas (Marsh et al., 2013).

Essas condições de exposição parcial conformam o modelo para aplicação de sensoriamento remoto para determinar a presença e extensão desse perfil.

Tratando-se do sensor ETM+ do satélite Landsat 7, esse capta a radiação solar que, após incidir na superfície terrestre, é refletida com modificações em sua frequência, a qual varia de acordo com o objeto refletor. Quando esse objeto se trata do meio geológico, distintas mineralogias influem na reflectância dessa radiação. Assim, horizontes de intemperismo compostos por diferentes conjuntos mineralógicos refletem, quando expostos, distintamente a luz solar incidente, o que permite aplicar essas imagens satelitais para distinguir suas respostas espectrais (Drury, 1993).

Essa distinção entre horizontes pode ainda ser auxiliada por modelos digitais de elevação e declividade do relevo, dado que essas assembleias mineralógicas diferem verticalmente, acompanhando determinadas características do relevo (Marsh et al., 2013).

No presente trabalho foi aplicada, além das composições de bandas, a subdivisão do perfil laterítico apresentada por Andrews Deller (2006), onde o autor utiliza determinadas associações mineralógicas para separar o perfil em horizontes de intemperismo.

As associações mineralógicas e sua organização vertical são típicos de perfis lateríticos, permitindo associar distintas reflectâncias com conjuntos mineralógicos condizentes com horizontes de intemperismo (Figura 2 e 3) (Drury, 1993; Andrews Deller, 2006).

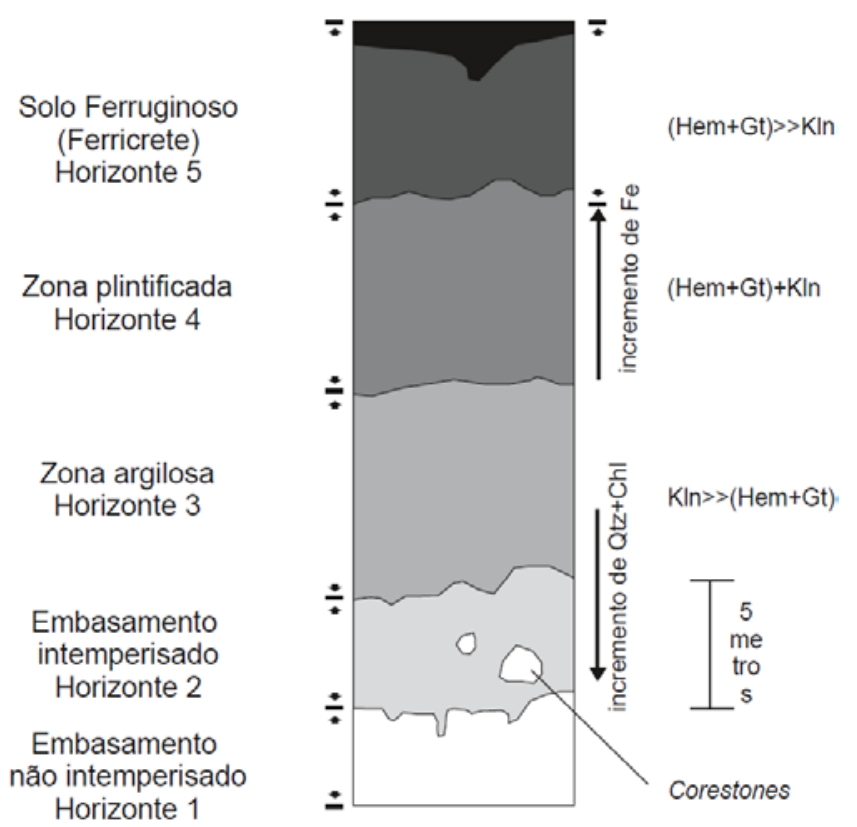

Figura 2. Variações mineralógicas ao longo do perfil laterítico típico aplicado por Andrews Deller (2006) para sensoriamento remoto via imagens Landsat7/ETM+. Hem - hematita, Gt - goethita, Kln - caulinita, Qz - sílica (quartzo + calcedônia), Chl clorita. 


\begin{tabular}{|l|l|l|}
\hline \multicolumn{1}{|c|}{ Unidade verificada em campo. } & \multicolumn{1}{c|}{ RGB 742 } & \multicolumn{1}{c|}{ RGB 754 } \\
\hline Solo ferruginoso (ferricrete) - horizonte 5 & $\begin{array}{l}\text { Castanho (amarronzado)/vermelho } \\
\text { amarronzado escuro }\end{array}$ & Verde oliva \\
\hline Influência mesclada dos horizontes 5 e 4 & - & Verde oliva escuro \\
\hline Caulinítico ferruginoso - horizonte 4 & Marrom/verde amarronzado & Verde claro \\
\hline Caulinítico - horizonte 3 & Ciano & Ciano \\
\hline Saprolito pouco alterado - horizonte 2 & Rosa a branco & Rosa pálido \\
\hline Vegetação & Verde & Azul escuro \\
\hline
\end{tabular}

Figura 3 - Respostas para diferentes fácies do perfil laterítico de acordo com a composição RGB de bandas do sensor Landsat-7/ETM+ (Andrews Deller, 2006).

De acordo com Drury (1993) e Andrews Deller (2006) as composições RGB (Red, Green and Blue) permitem individualizar a hematita (horizonte 5) da goethita (transição dos horizontes 5 e 4 e horizonte 4), através da banda 2, dado a menor reflectância do segundo mineral; a banda 4 mostra boa diferenciação de quartzo e caulinita para os óxidos e hidróxidos de ferro, enquanto a banda 5 distingue a clorita (horizonte 3 , quando bissialítico) da caulinita, com maior reflectância do segundo, e a banda 7 distingue minerais portadores de hidroxila (Figura 4).

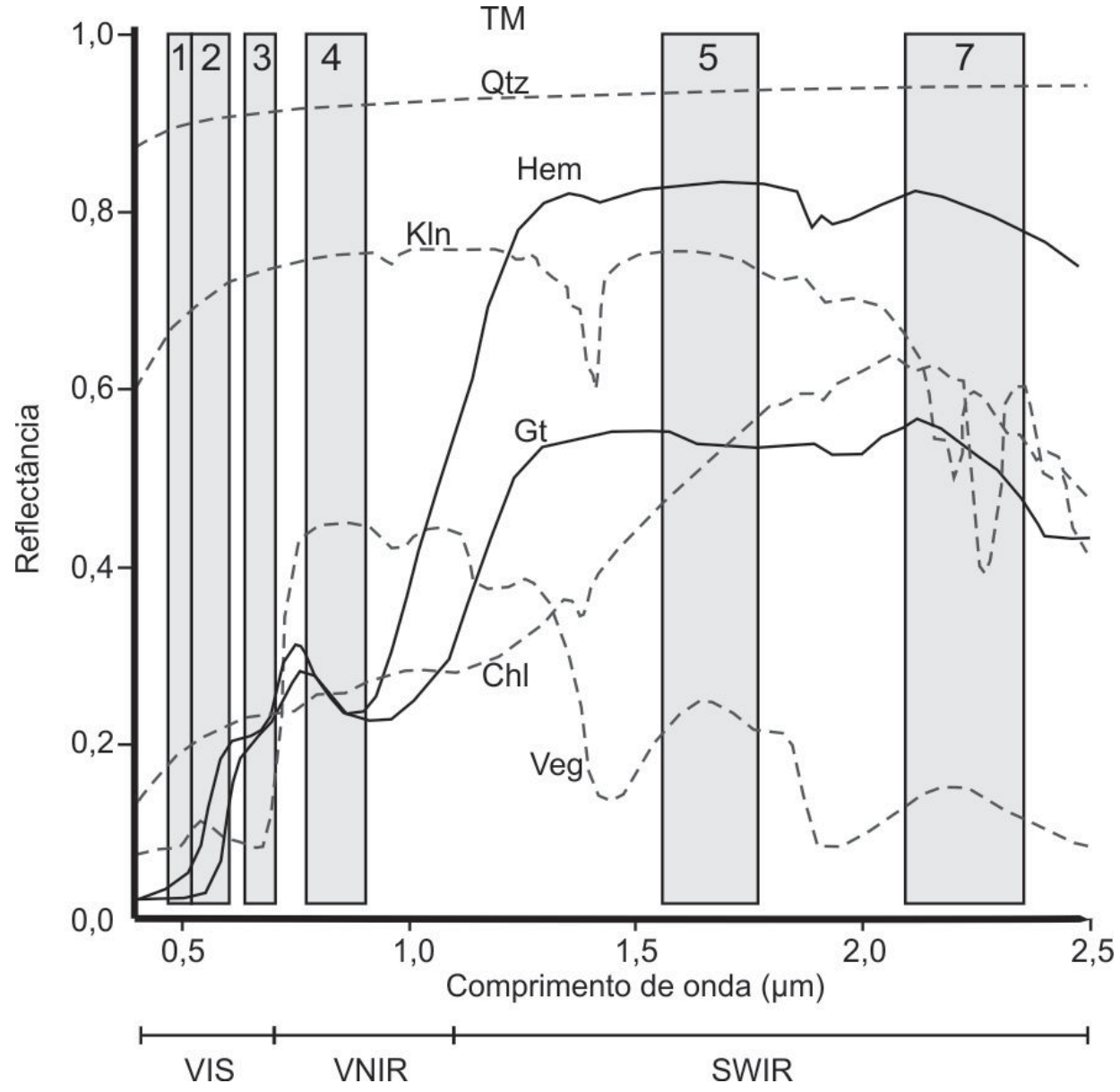

Figura 4. Comportamento dos espectros dos minerais presentes nos horizontes lateríticos e características que podem ser analisadas com as bandas da imagem Landsat-7/ETM+. (Qtz - quartzo; Hem - hematita; Kln - caulinita; Gt - goethita; Chl clorita; Veg - vegetação) (Adaptado de Drury, 1993; Andrews Deller, 2006).

Tomando as composições de bandas RGB 754 e 742, foi feita uma delimitação manual das regiões onde se destacaram as respostas dos horizontes de intemperismo condizentes com aquelas aplicadas por Andrews Deller (2006). Como as de exposição de horizontes de intemperismo se associam a determinadas regiões e posições do relevo (Marsh et al., 2013), os modelos digitais de elevação e declividade contribuíram para essa delimitação manual. Por fim, essas delimitações em sensoriamento remoto foram comparadas com os horizontes de intemperismo descritos em campo, buscando, assim, identificar relações que corroborem a aplicação dessa investigação indireta para perfis lateríticos. 


\section{RESULTADOS E DISCUSSÕES}

\section{Geologia Local}

$\mathrm{Na}$ área foram descritos gnaisses, cloritaanfibólio xistos e quartzitos, os quais mostram foliação subvertical, orientada segundo a direção NW-SE. A direção é paralela aos contatos tectônicos entre esses litotipos, feitos por zonas de cisalhamento.

Também foram identificados 2 distintos

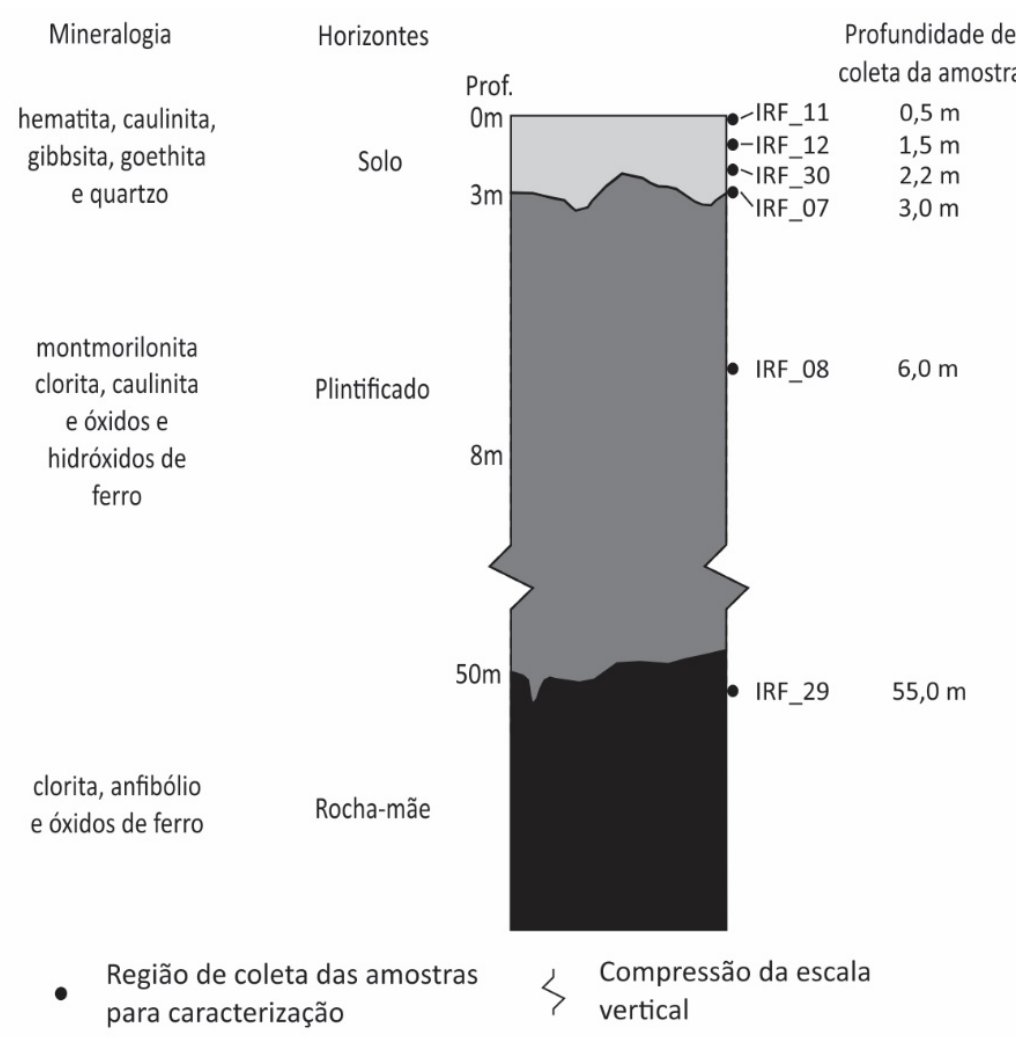

Figura 5. Perfil de intemperismo esquemático, profundidade de coleta de amostras e resultados da caracterização mineralógica do clorita-anfibólio xisto e respectivos horizontes de intemperismo. As profundidades das amostras são relacionadas ao ápice topográfico do platô no domínio do litotipo (cota de 1150 m).

\section{Horizonte 5}

O horizonte 5 é observado nas regiões topograficamente mais altas e com menor declividade do relevo, com espessura da ordem de $3 \mathrm{~m}$ em sua melhor exposição em corte de estrada.

Pode ser encontrado nos domínios do clorita-anfibólio xisto e dos gnaisses, estando ausente nos quartzitos, em região coincidente com a porção onde se tem maior dissecação do relevo, à SSW do corpo de xisto metaultramáfico.

Este horizonte apresenta solo de cor predominantemente vermelha (Figura 6), argilosos, com presença de nódulos ferruginosos e baixa contribuição de quartzo visível (inferior a 10\%).

São homogêneos e, por serem muito evoluídos, na ausência do afloramento de horizontes de intemperismo desenvolvidos a partir desses litotipos. O domínio de rocha metaultramáfica apresenta 0 perfil mais representativo, havendo informações do topo, porção intermediária e da rocha. Por esse motivo, o domínio desse xisto metaultramáfico foi tomado para a caracterização mineralógica do perfil laterítico (Figura 5). 


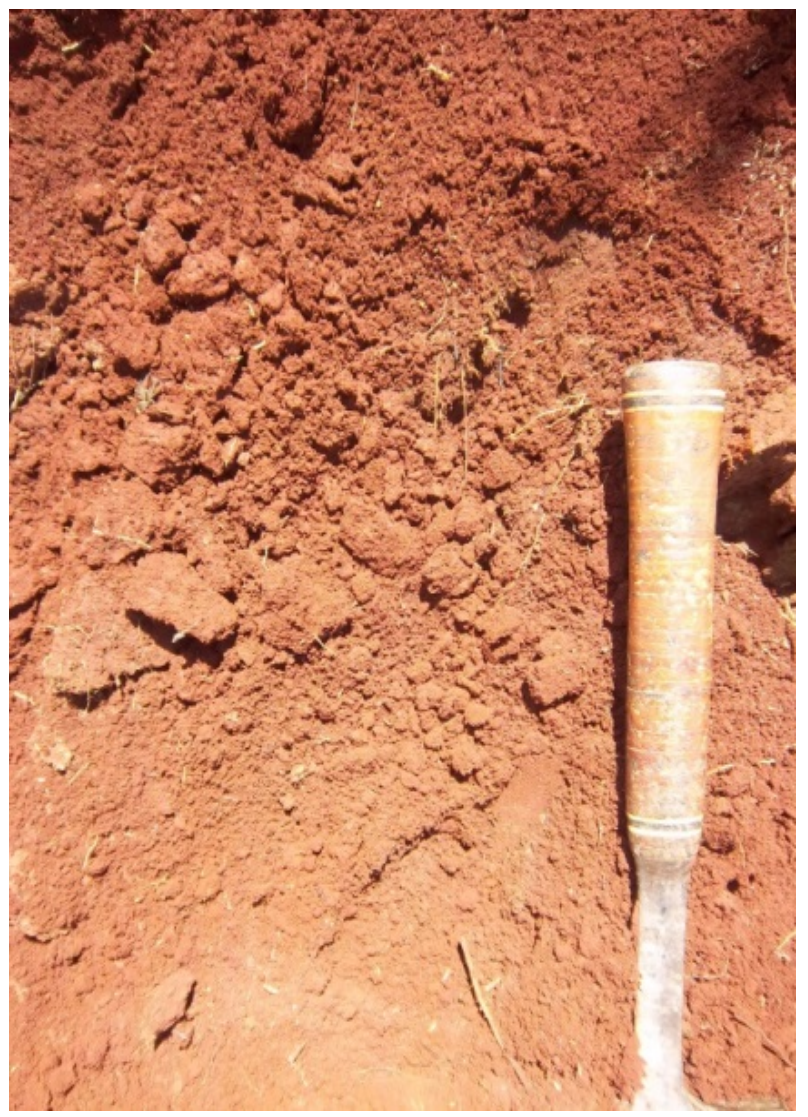

Figura 6 - Latossolo vermelho argiloso desenvolvido a partir de clorita-anfibólio xisto, se sobrepondo ao horizonte de plintificado.
Nessa transição já é possível identificar influência das estruturas presentes na rocha, a exemplo do domínio de gnaisses, que apresenta níveis cauliníticos de cor branca intercalados com porções composta por caulinitas e minerais ferruginosos, resultando em cor vermelha, refletindo fortemente o bandamento gnáissico (Figura 8).

No domínio de rocha metaultramáfica, partindo do topo aplanado para os rumos NW e SE podem ser identificados solos similares àqueles do horizonte 5 , porém em posição topográfica correspondente ao horizonte plintificado (descrito abaixo).

Nesse caso identificou-se menor presença de minerais ferruginosos se comparados àqueles solos do topo do platô, o que pode ser determinado com auxílio de imã.

As variações na posição topográfica, menor presença de óxidos de ferro e baixa declividade do relevo no local sugerem que esse solo possa ter se desenvolvido em momento posterior ao intemperismo que formou o perfil laterítico, tendo sido originado diretamente a partir do horizonte plíntico.

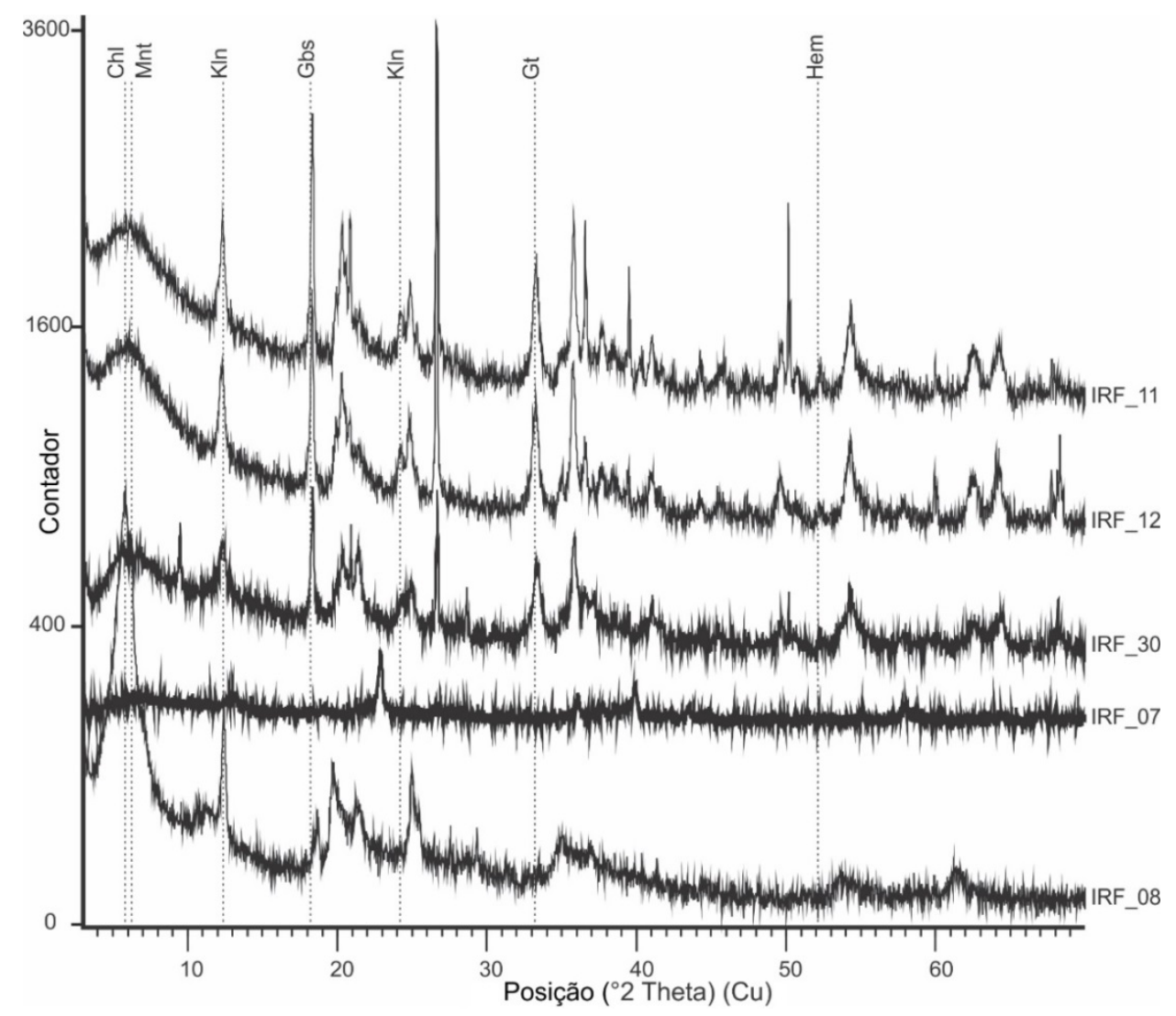

Figura 7 - Difratograma de raios X de amostras do perfil de intemperismo. O empilhamento dos difratogramas reflete a distribuição em profundidade das amostras coletadas. (Abreviações: Chl - clorita, Mnt - montmorillonita, Kln caulinita, Gbs - gipsita, Gt - goethita, Hem - hematita). 


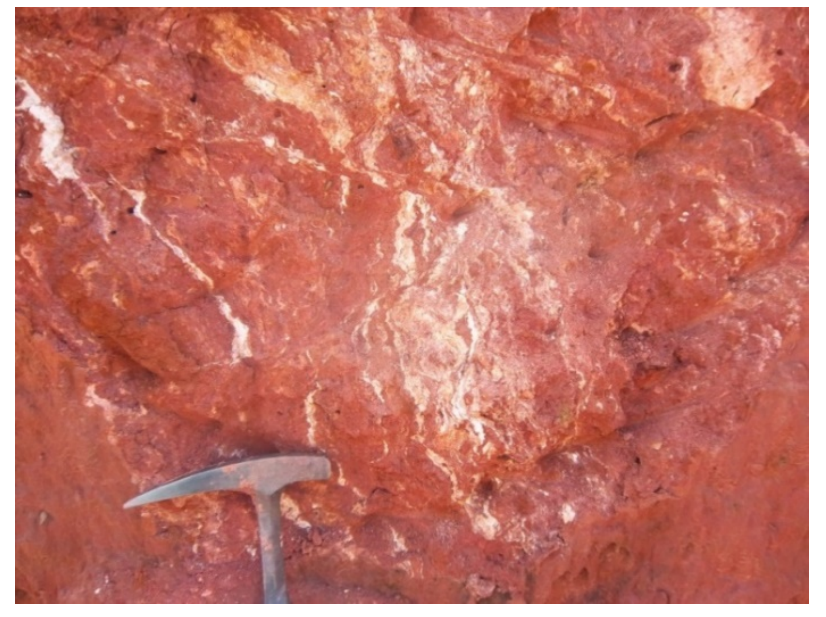

Figura 8. Transição entre os horizontes 5 e 4 no domínio de gnaisses. Ocorrem caulinitas e minerais ferruginosos, em cor vermelha, e bolsões de caulinita com cor branca, preservando parte do bandamento da rocha.

\section{Horizonte 4/3}

Não foram observados os horizontes 4 e 3 da forma exata proposta no perfil laterítico típico (Figura 2). No domínio de rocha metaultramáfica identificou-se um horizonte plintificado, porém, com presença de argilas bissialíticas (Figura 7), ao invés de caulinitas, o que se deve às características da rocha original. Nos quartzitos foram descritas caulinitas acompanhadas de diminuta presença de hidróxidos de ferro no mesmo nível topográfico das montmorillonitas do domínio metaultramáfico. Já nos gnaisses, que se posicionam em área com menor inserção erosiva, observou-se apenas a transição do horizonte 5 para o 4 . Dadas essas condições, onde os aspectos dos horizontes 4 e 3 não se apresentam com a exata descrição do perfil típico (Figura 2), havendo, até mesmo, argilas monossialíticas e bissialíticas em um mesmo nível topográfico, mas em domínios litológicos distintos, optou-se por agrupar esses como horizonte 4/3. Dessa forma, reflete a porção intermediária do perfil de intemperismo utilizado por Andrews Deller (2006) em seu modelo, excetuando aqui o horizonte 2, onde já seriam discerníveis núcleos de rocha preservados (corestones) em meio ao saprolito.

Esses horizontes agrupados se posicionam topograficamente abaixo do horizonte 5, expostos em áreas de maior declividade ou então em cortes de estrada. Estima-se uma espessura que pode chegar a $50 \mathrm{~m}$, tomando como nível basal os afloramentos de rocha não intemperizada de quartzitos e xistos metaultramáficos.
No clorita-anfibólio xisto esse horizonte saprolítico possui cor verde com plintitas de cor ocre. Posicionado abaixo do horizonte de solos, mostra, no local, espessura aflorante de $5 \mathrm{~m}$. As plintitas possuem formato esférico e diâmetro subcentimétrico. Também podem ser encontradas faixas de cor ocre, obedecendo a planos pré-existentes (Figura 9), com continuidade variada e espessura geralmente inferior a $5 \mathrm{~cm}$, representando, no máximo, 25\% do saprolito. Nesses planos pré-existentes podem se formar, até mesmo, nódulos de minerais ferrosos, com tamanho inferior a $1 \mathrm{~cm}$.

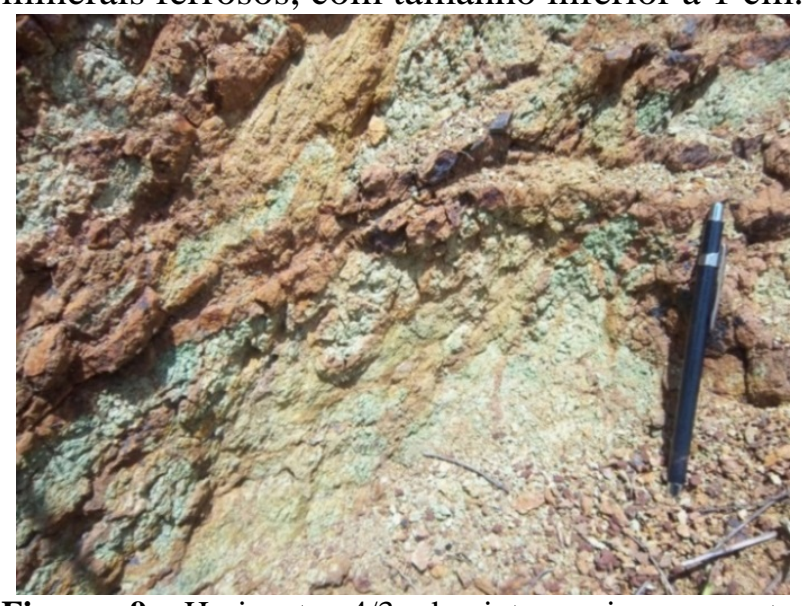

Figura 9. Horizonte $4 / 3$ de intemperismo, mostra saprolito plintificado desenvolvido a partir de cloritaanfibólio xisto, com cores verde e ocre.

Enquanto isso, no domínio dos quartzitos é observado saprolito com cor ocre claro a amarelo pálido, friável, com diminuta contribuição de minerais ferrosos. A caulinita, de cor branca, é observada preenchendo vazios entre os grãos de quartzo da rocha intemperizada. Dada à propriedade friável do saprolito e menor contribuição de argilas, os aspectos originais da rocha são menos distinguíveis do que no clorita-anfibólio xisto.

\section{Horizonte 2}

Não se observou representante correlacionável ao horizonte 2 do perfil típico (Figura 2), descrito como saprolito que marca a transição do perfil de intemperismo para a rocha. Esse fato possivelmente se deve a sua não exposição, motivo, então, de não constar aqui sua descrição ou caracterização mineralógica.

\section{Horizonte 1}

Esse horizonte pôde ser observado apenas nos domínios do quartzito e do clorita-anfibólio xisto. Em ambos os casos foi encontrado aproximadamente $50 \mathrm{~m}$ abaixo do ápice do 
platô de referência local, presente no domínio de xisto metaultramáfico. O clorita-anfibólio xisto mostra cor verde escuro, com foliação marcada por cristais de clorita, com hábito planar e tamanho inferior a $0,5 \mathrm{~cm}$, que se orientam de forma subvertical na direção NWSE. Os cristais de anfibólio ocorrem como ripas menores que $0,5 \mathrm{~cm}$, paralelas à direção da foliação. Em análise de campo não foram identificados, nesse afloramento, a presença de cristais neoformados por processos intempéricos. Os quartzitos apresentam cor branco, não friável, onde se distingue desplacamento com alto ângulo orientado na direção NW-SE. Possivelmente esse plano está associado à foliação, no entanto, a pureza em grãos de quartzo, que são de granulometria média, e ausência de micas dificulta essa conclusão.

\section{Sensoriamento Remoto.}

Uma vez concluída a caracterização do perfil laterítico, foram analisadas as composições de bandas RGB 742 e 754 utilizadas por Andrews Deller (2006) para distinção de horizontes de intemperismo, associadas aos modelos digitais de elevação e declividade do relevo, com resultados espectrais resumidos na figura $10 \mathrm{e}$ visíveis na figura 11 .

\begin{tabular}{|l|l|l|}
\hline Indícios de Unidade & RGB 742 & RGB 754 \\
\hline Horizonte 5 & Vermelho & Vermelho \\
\hline Transição horizontes 5 e 4 & - & Verde oliva escuro \\
\hline Horizonte 3 & Ciano & Ciano \\
\hline Vegetação & Verde & Azul \\
\hline
\end{tabular}

Figura 10 - Indícios obtidos para as composições de banda Landsat-7/ETM+ que são sugestivos de diferentes horizontes do perfil laterítico e de presença de vegetação.

As características dos horizontes de intemperismo delimitadas através de sensoriamento remoto se agrupam em situação associável ao perfil laterítico descrito em campo (Figura 12).

Esse perfil se prolonga pelo platô local, ocupando regiões com elevação de $1150 \mathrm{~m}$ até $1100 \mathrm{~m}$. Nas duas composições as manchas de cobertura vegetal causam dificuldades ao processo, apesar disso, não chegam a ser impeditivas.

A composição RGB754 mostra a influência da vegetação em cor azul. Em vermelho tem-se indícios do horizonte 5 , representado por solo ferruginoso, posicionado em área de topo do relevo e com baixa declividade. Apontam-se, em verde oliva, feições de transição entre os horizontes 5 e 4 , composta por mistura de contribuição de ambos os horizontes, a qual se situa nas meia-encostas de baixa declividade do domínio de rocha metaultramáfica.

Não se reconheceu as condições puramente indicativas do horizonte 4 , o que pode ser entendido como ausência de exposição ou ausência de características idênticas àquelas do perfil típico (Figura 2) usado como base para as composições de bandas. A resposta do horizonte 3 aparece em cor ciano, porém, não mostra forte destaque devido ao baixo contraste com as demais matizes de cor.
Na composição RGB742 a vegetação é destacada em cor verde. Dado a diferença de matizes de cor, nessa composição observa com maior facilidade os indícios do horizonte 3 , em ciano, presente nos domínios de gnaisses e quartzitos, posicionada, principalmente, em áreas de maior declividade e topograficamente abaixo do horizonte 5 . O equivalente ao horizonte superior, composto por solo ferruginoso, se destaca em cor vermelho a vermelho escuro/amarronzado.

No extremo sul da área pesquisada o compartimento de relevo orientado segundo a direção noroeste-sudeste apresenta aspectos de maior incidência erosiva, marcado por rebaixamento topográfico e maiores declividades, visível em ambas as composições. Essa região coincide com o domínio de quartzitos, onde se ausenta o equivalente ao horizonte 5 . Devido seu rebaixamento topográfico, é mais propícia à exposição de horizontes intermediários e inferiores do perfil laterítico.

No restante da área, onde se conforma um platô, o relevo apresenta topos de baixa declividade entrecortados por drenagens. Nesse caso, a transição do topo do platô para os fundos de vales, é marcada por extensas meiaencostas, com exemplos côncavos e convexos, de baixa declividade, geralmente inferior a $7^{\circ}$. 

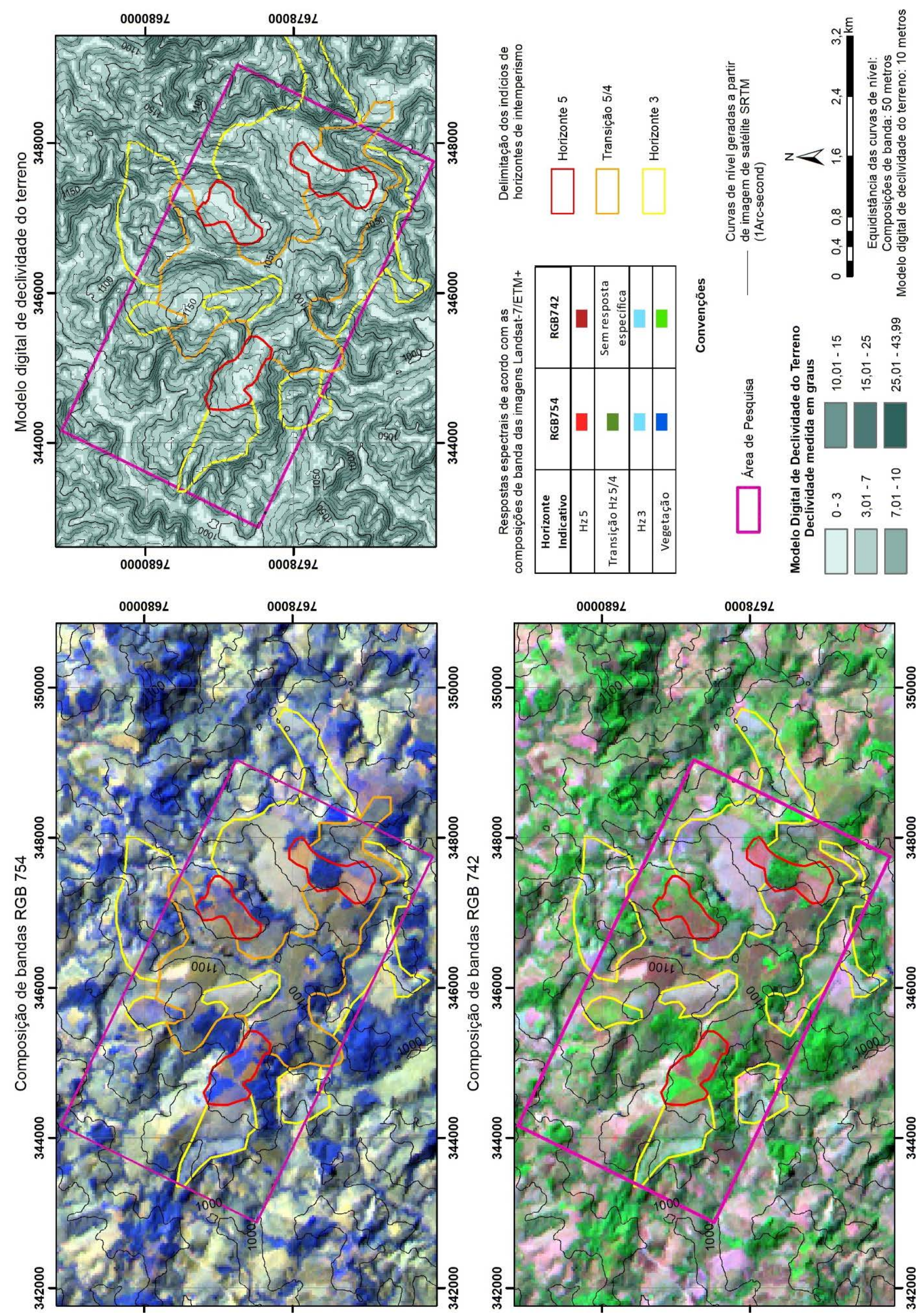

Figura 11 - Composições de bandas RGB 754 e 742 (Landsat-7/ETM+) e modelos digitais de elevação e declividade do relevo na área pesquisada. 


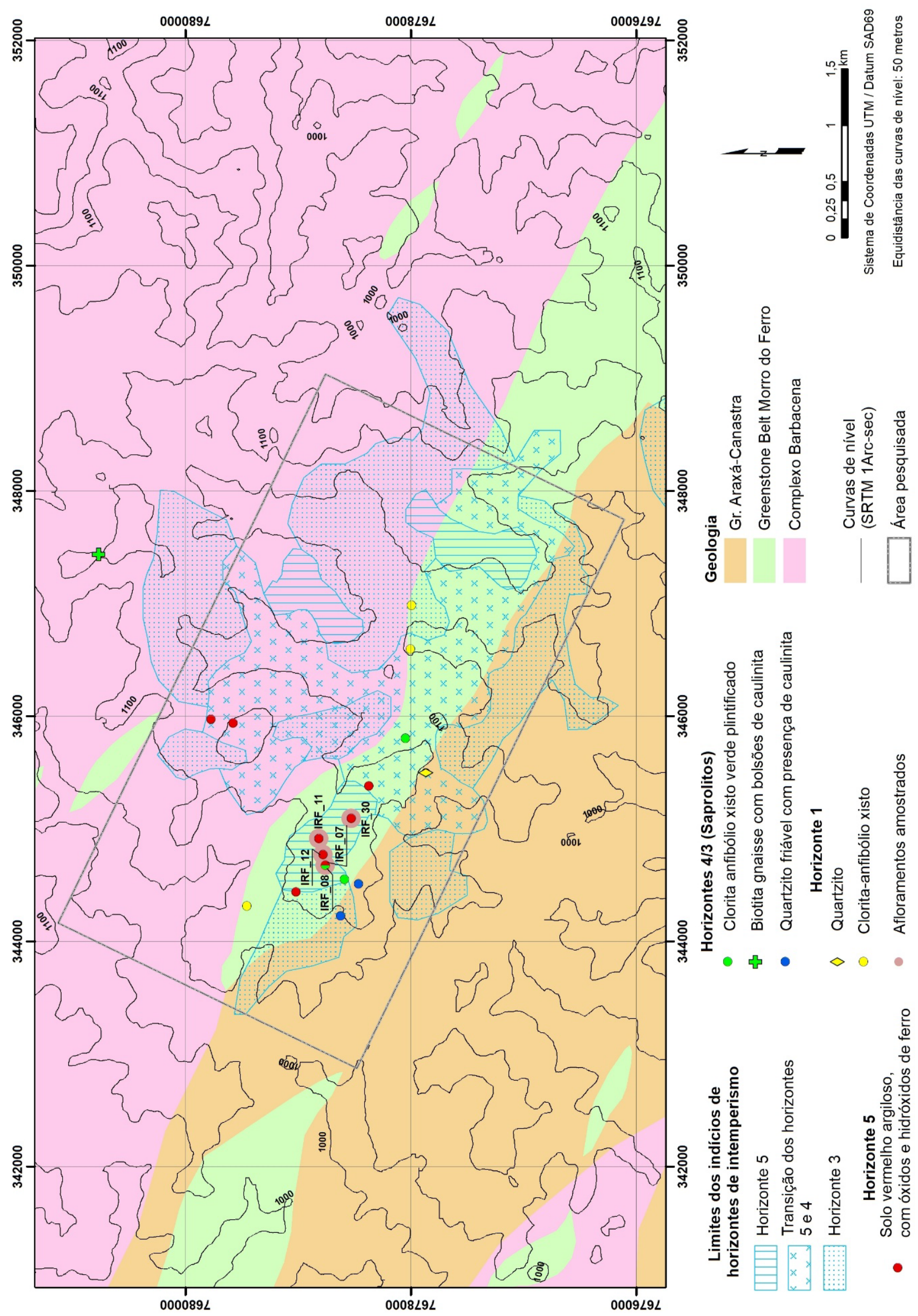

Figura 12. Mapa de detalhe da área de pesquisa destacando os horizontes interpretados a partir de sensoriamento remoto com imagens Landsat-7/ETM+ e modelos digitais de terreno. Observa-se ainda a distribuição de afloramentos visitados em campo. Base geológica adaptada de Zanardo (2003) e Feola (2004). 
As respostas espectrais do horizonte 5 nas composições de bandas são atreladas ao conteúdo de óxidos de ferro. Esses minerais são os principais responsáveis pela reflectância obtida nessas composições (Andrews Deller, 2006).

Originalmente a transição entre os horizontes 5 e 4 é marcada pela soma de influências do solo ferruginoso e do horizonte plintificado (Andrews Deller, 2006). Aqui se associa a região onde os solos do domínio metaultramáfico localizados em meia-encosta de baixa declividade, em posição topográfica equivalente à do horizonte plintificado, onde, em descrições de campo, identificou-se menor presença de óxidos de ferro se comparado ao solo muito evoluído do topo do platô.

Essa diferença de conteúdo de minerais ferruginosos nas duas posições de relevo parece ser 0 fator responsável por essa resposta espectral. Assim, o aspecto de transição desses horizontes no sensoriamento remoto estaria associado à proposta previamente apresentada de que esses são solos mais jovens do que aqueles do topo do platô, e teriam se desenvolvido diretamente a partir do horizonte plintificado.

No domínio de quartzitos foram identificadas respostas espectrais do horizonte 3 se sobrepondo aos afloramentos descritos em campo como do horizonte 4/3. Já no caso do xisto metaultramáfico, a melhor exposição do horizonte $4 / 3$ se deu em corte de estrada, não cabendo então resposta espectral.

As respostas espectrais aqui obtidas majoritariamente como indicativas do horizonte 3 são entendidas como devido à exposição de horizontes portadores de argilas cauliníticas e diminuta presença de óxi-hidróxidos de ferro (Andrews Deller, 2006).

Assim, as respostas mais expressivas se dão em domínios de gnaisses e quartzitos, mais favoráveis a gênese de caulinitas pelo processo laterítico (Tardy et al., 1973). Junto a isso, a posição no relevo, com erosão expressiva dos horizontes superiores, ricos em minerais ferruginosos, e impossibilidade continuidade dos processos intempéricos, que poderiam resultar na continuidade de neoformação de óxi-hidróxidos de $\mathrm{Fe}$, são entendidos como principais condicionantes para obtenção da resposta desse horizonte.
Diferente disso, a ausência de condicionantes similares impossibilitou a observação de respostas espectrais tipicamente do horizonte 4.

As mudanças mineralógicas tratadas com base em descrições de campo mostram respaldo nas caracterizações mineralógicas por difratometria de raio X (Figura 6).

Nesse se observa uma diminuição da expressão dos picos de minerais ferruginosos à medida que se desce no perfil de intemperismo, enquanto se mantém as respostas para caulinitas.

Como tratado, as montmorillonitas identificadas no horizonte saprolítico do domínio metaultramáfico se expõem em corte de estrada, impedindo a observação de suas respostas espectrais em imagem de satélite.

A aplicação do sensoriamento remoto exibiu descontinuidades e oscilações nos níveis topográficos dos polígonos delimitados como indícios dos horizontes de intemperismo. Essas situações podem ser explicadas por influências geológico-estruturais, dado que os litotipos e condições de drenagem interferem na gênese do perfil de intemperismo e nas respectivas espessuras dos horizontes.

A cobertura vegetal, a sobreposição de processos de intemperismo e a não exposição, como potencialmente ocorre com o horizonte 2 , também influenciam nessas extensões delimitadas. Da mesma forma, o horizonte 1 (rocha não intemperizada) encontra-se exposto somente pequenas áreas, não sendo representativos na escala da imagem Landsat 7/ETM+.

Dessa forma, o sensoriamento remoto não permitiu mapear, continuamente, a distribuição dos horizontes lateríticos, principalmente devido a relação resolução/escala de aplicação. No entanto, não se espera que, em especial nessa escala, essa seja sua finalidade. Entendese que sua aplicação seja voltada, nesse caso, ao levantamento de aspectos indicativos da preservação e exposição de horizontes de intemperismo que possam ser parte de um perfil laterítico.

Com isso, seu caráter é prospectivo para esses produtos de intemperismo. Já o mapeamento desses perfis, com delimitação pontual dos horizontes, exige caracterizações químico-mineralógicas, somente possível 
acessando o perfil laterítico.

Outro ponto interessante a se destacar é o fato de que, originalmente, as composições de bandas foram aplicadas por Andrews Deller (2006) em região de clima árido.

Naquele caso se nota baixa cobertura vegetal, condições de relevo favoráveis à exposição dos horizontes e preservação do perfil laterítico, sem incidência de processos intempéricos posteriores a sua formação. Em contrapartida, aqui foi possível obter respostas espectrais condizentes com horizontes de intemperismo mesmo havendo influências de cobertura vegetal e de potencial sobreposição de processos intempéricos, como ficou indicado no domínio de rocha metaultramáfica.

\section{CONCLUSÕES}

O estudo da geologia local permitiu descrever três distintos litotipos que foram afetados por processo laterítico, tendo, parte do seu perfil, sido preservado dos processos erosivos. Esse perfil laterítico é entendido como parte integrante da unidade geomorfológica Planalto Poços de Caldas-Varginha. Assim, é representante de um extenso domínio que preserva horizontes de intemperismo em uma extensa área do sudoeste de Minas Gerais.

A variação mineralógica descrita nesse perfil, assim com as associações de minerais neoformados, são condizentes com o que se identifica em um perfil laterítico (Tardy et al., 1973; Marsh et al., 2013). Por sua vez, esse modelo de distribuição mineralógica embasa a aplicação do sensoriamento remoto com imagens Landsat-7/ETM+ (Drury, 1993), explicando, então, as respostas espectrais obtidas.

As composições de bandas RGB 754 e 742, somadas aos modelos digitais de elevação e declividade do relevo, tiveram resultados relacionáveis aos horizontes de intemperismo descritos em campo. Também foram compatíveis com os resultados de Andrews
Deller (2006), mesmo em distinta escala de trabalho, com interferências de cobertura vegetal e baixa declividade do relevo, fatores que dificultam as exposições de horizontes de intemperismo e favorecem processos de intemperismo mais jovens que o perfil laterítico (Marsh et al., 2013).

Ainda assim, se interpreta os resultados obtidos em sensoriamento remoto como encorajadores para replicações em situação prospectiva. Com isso, podem ser utilizados na busca de evidências que corroborem a preservação de horizontes de intemperismo, contribuindo, entre outros, para subsidiar sequentes estudos in loco. Assim, as composições aqui testadas são, entre outras possíveis, potenciais ao uso na investigação de perfis lateríticos.

Para isso, a adição dos modelos de elevação e declividade apresentou grande contribuição auxiliar na delimitação das respostas espectrais de cada horizonte. Atualmente as imagens Landsat 8 OLI/TIRS apresentam um vasto banco de dados com larga disposição temporal, podendo subsidiar avaliações a exemplo dessa aqui aplicada.

\section{AGRADECIMENTOS}

Ao CNPq pelo fomento da pesquisa através do Processo 131324/2013-6, ao Prof. Dr. Antenor Zanardo pela contribuição e aos revisores anônimos por correções e excelentes sugestões.

\section{REFERÊNCIAS}

ALMEIDA, F.F.M. O Cráton do Paramirim e suas relações com o do São Francisco. In: SIMPÓSIO SOBRE O CRÁTON DO SÃO FRANCISCO E SUAS FAIXAS MARGINAIS, 1981, Salvador. Anais... Salvador: Sociedade Brasileira de Geologia, 1981, p.1-10.

ANDREWS DELLER, M.E. Facies discrimination in laterites using Landsat Thematic Mapper, ASTER and ALI dataexamples from Eritrea and Arabia. International Journal of Remote Sensing, v. 27, n. 12, p. 2389-2409, 2006. http://dx.doi.org/10.1080/01431160600586050

BRAND, N.W.; BUTT, C.R.M.; ELIAS, M. Nickel laterites Classification and features. AGSO Journal of Australian Geology and Geophysics, v. 17, p. 81-88, 1998.

BUTT, C.R.M. Nickel laterites and bauxites. CSIRO
Australia, Division of Mineralogy. Perth. Report, 34p., 1975. BRITO NEVES, B.B.; CAMPOS NETO, M.C.; FUCK, R.A. From Rodinia to Western Gondwana: An approach to the Brasiliano-PanAfrican cycle and orogenic collage. Gondwana Research, v. 22, n. 3, p.155-166, 1999.

CARVALHO, S.G.; SOARES, P.C.; BARBOUR, A.P. Mineralizações nos terrenos greenstone de Alpinópolis e Fortaleza de Minas. Geociências, v. 11, n. 1, p.19-47, 1992.

DARDENNE, M.A. \& SCHOBENHAUS, C. Metalogênese do Brasil. Brasília: CPRM, Editora UnB, 392p, 2001.

DOGAN, H.M. Mineral composite assessment of Kelkit River Basin in Turkey by means of remote sensing. Journal of Earth Systems Science, p. 701-710, 2009. http:// dx.doi.org/10.1007/s12040-009-0059-9 
DRURY, S.A. Image interpretation in geology. Second edition. Ed. Chapman \& Hall. London. 1993. http://dx.doi.org/10.1007/978-94-010-9393-4

FEOLA, J.L. Mineralizações auríferas hospedadas na faixa metavulcano-sedimentar Jacuí-Bom Jesus da Penha Sudoeste de Minas Gerais. Rio Claro, 2004. 211p. Tese (Doutorado), Instituto de Geociências e Ciências Exatas, Universidade Estadual Paulista.

HASUI, Y.; RODRIGUES, E.P.; OLIVEIRA, M.C.B.; HENS, J.; MORALES, N.; ZANARDO, A.; QUADE, H.; NYK, R.; KULLER, M.L.; FRASCA, M.H.B.O. Deformação por cisalhamento dúctil: modelo de transformação de rochas pré-cambrianas antigas do leste de São Paulo. Fase I, Instituto de Pesquisas Tecnológicas, São Paulo, Relatório IPT n. 25908, v. 3, 1988.

MADEIRA, J.; BEDIDI, A.; CERVELLE, B.; POUGET, M.; FLAY, N. Visible spectrometric indices of hematite (Hm) and goethite (Gt) content in lateritic soils: the application of a Thematic Mapper (TM) image for soil-mapping in Brasilia, Brazil. International Journal of Remote Sensing, v. 18, p. 2835-2852, http://dx.doi.org/10.1080/014311697217369

MARSH, E.; ANDERSON, E.; GRAY, F. Nickel-cobalt laterites- A deposit model, chapter of Mineral deposit models for resource assessment. U.S. Geological Survey Scientific Investigations Report, 2010, 38p., 2013.

MELFI, A.J.; TRESCASES, J.J.; OLIVEIRA, S.M.B. Les "laterites" nickeliferes du Brésil. Cah. Orstom, Série Geológica, v. 11, p. 15-42, 1980.

MORALES, N. Evolução tectônica do Cinturão de Cisalhamento Campo do Meio na porção ocidental. Rio Claro, 1993. 256p. Tese (Doutorado), Instituto de Geociências e Ciências Exatas, Universidade Estadual Paulista.

RADAMBRASIL. Levantamento dos recursos naturais Folhas SF 23/24, Rio de Janeiro/Vitória. Rio de Janeiro, v. 32. 780p. 1983.

RETALLACK, G.J. Lateritization and bauxitization events. Economic Geology, v. 105, p. 655-667, 2010. http://dx.doi.org/10.2113/gsecongeo.105.3.655

SIMÕES, L.S.A. Evolução tectono-metamórfica da Nappe de Passos, sudoeste de MG. São Paulo, 1995. 149p. Tese (Doutorado), Instituto de Geociências, Universidade de São Paulo.

SMIRNOV, V.I. Geologia de yacimientos minerales. Edición Española. Ed. Mir Moscow, 654p., 1982.

SOE, M.; WON-INB, KRIT; TAKASHIMAC, ISAO; E CHARUSIRID, PUNYA. Lateritic soil mapping of the Phrase basin, northern Thailand using satellite data. Science Asia, v. 34, p. 307-316, 2008. http:// dx.doi.org/10.2306/ scienceasia1513-1874.2008.34.307

TARDY, Y.; BOQUIER, G.; PAQUET, H.; MILLOT, G. Formation of clay from granite and its distribution in relation to climate and topography. Geoderma, v. 10, p. 271-184, 1973.

TEIXEIRA, N.A. Geologia e petrologia e prospecção geoquímica da sequência vulcano-sedimentar Morro do Ferro, Fortaleza de Minas (MG). Brasília, 1978. 202p. Dissertação (Mestrado), Instituto de Geociências, Universidade de Brasília.

TEIXEIRA, N.A. \& DANNI, J.C.M. Petrologia de lavas metabásicas da Sequência Morro do Ferro, Fortaleza de Minas (MG). Revista Brasileira de Geociências, v. 9, n. 2, p. $151-158,1979$.

THORNE, R.L. Nickel laterites, origin and climate. Southampton, 2011. Tese (Doutorado) - Faculty of Engineering, Science and Mathematics, Southampton University.

VALERIANO, C. M.; MACHADO, N.; SIMONETT, I. A.; VALLADARES, C. S.; SEER, H. J.; SIMÕES, L.S. U-Pb geochronology of the southern Brasília Belt (SE Brazil): sedimentary provenance, Neoproterozoic orogeny and assembly of West-Gondwana. Precambrian Research, v. 130, n. 1, p. 27-55, 2004.

ZANARDO, A.; MORALES, N.; CARVALHO, S.G. Evolução metamórfica da porção sul do Cráton Paramirim. In: CONGRESSO BRASILEIRO DE GEOLOGIA, 36, 1990, Natal. Anais... Natal: Sociedade Brasileira de Geologia, v. 4, p. 1945-1951.

ZANARDO, A. Análise petrografia, estratigráfica e microestrutural da região de Guaxupé-PassosDelfinópolis (MG). Rio Claro, 1992. 270p. Tese (Doutorado), Instituto de Geociências e Ciências Exatas Universidade Estadual Paulista.

ZANARDO, A. Pesquisa geológica e de matérias-primas cerâmicas do centro nordeste do Estado de São Paulo e vizinhanças: sistematização crítica da produção técnicocientífica. Rio Claro, 2003. Tese (Livre Docência), Instituto de Geociências e Ciências Exatas - Universidade Estadual Paulista. 